\title{
A REVERBERAÇÃO TEXTUAL EM QUE FIM LEVARAM TODAS AS FLORES, DE OTTO LEOPOLDO WINCK
}

\section{THE TEXTUAL REVERBERATION IN QUE FIM LEVARAM TODAS AS FLORES, BY OTTO LEOPOLDO WINCK}

\author{
Ariane Regina de Oliveira Hidalgo* \\ Márcio Pereira Ribeiro**
}

Resumo: Este artigo objetiva verificar a presença de outros textos literários no romance Que fim levaram todas as flores (2019), de Otto Leopoldo Winck. O autor, que, além de romancista e poeta, é Doutor em Estudos Literários, leciona disciplinas de Escrita Criativa, cursos que serviram como inspiração na construção do enredo no romance. Partindo desse pressuposto, serão abordados alguns textos cujas ideias sobressaem na narrativa através da alusão, do "plágio" e de ecos textuais. Com base nas teorias da intertextualidade, do dialogismo e outras, esse estudo pretende demonstrar como a obra dialoga com textos literários que a antecederam, usando-os no escopo do romance.

Palavras-chave: Intertextualidade; Transtextualidade; Intermidialidade.

Abstract: This article tries to verify the presence of other literary texts occurs in the novel Que fim levaram todas as flores (2019), by Otto Leopoldo Winck. The author, in addition to being a novelist and poet, is a Ph.D. in Literary Studies. He works as a professor of Creative Writing, courses that are inspiration for the construction of the plot in the novel. Based on this assumption, some texts will be approached whose ideas stand out in the narrative through the allusion, "plagiarism", and textual echoes. Based on the theories of intertextuality, dialogism and others, this study intents to demonstrate how the related work dialogues with literary texts that preceded it, using them within the scope of the novel.

KEYworDs: Intertextuality; Transtextuality; Intermediality.

\footnotetext{
"Mestranda do Programa de Pós-Graduação em Teoria Literária do Centro Universitário Campos de Andrade (UNIANDRADE). E-mail: arianeliteraturaeletras@gmail.com.

${ }^{* *}$ Mestre em Teoria Literária pelo Centro Universitário Campos de Andrade (UNIANDRADE) e doutorando do Programa de Pós-Graduação em Teoria Literária do Centro Universitário Campos de Andrade (UNIANDRADE). E-mail: marciodoutorado@gmail.com.
} 


\section{INTRODUÇão}

Pretendemos neste artigo analisar, à luz de teorias que tratam da intertextualidade, o romance Que fim levaram todas as flores (2019) do poeta, professor universitário, pesquisador de literatura e romancista laureado com o Prêmio Nacional de Literatura da Academia de Letras da Bahia, pela obra Jaboc (2006), Otto Leopoldo Winck. O autor faz uso de sua experiência como professor na disciplina de Escrita Criativa, dialogando com o enredo de seu romance Que fim levaram todas as flores (2019) outros textos clássicos da literatura mundial. Assim, neste estudo buscou-se analisar de que forma a intertextualidade se sobressai na narrativa e dialoga com a obra em questão, contribuindo, então, para a construção de significado do texto.

Inicialmente, realizamos uma leitura pormenorizada do texto, a fim de encontrarmos o máximo de vestígios de outras obras presentes na narrativa, não apenas daqueles textos e referências mais evidentes, mas também daqueles que surgem na forma de alusões. Em seguida, foram realizados estudos comparativos entre a obra previamente elencada e alguns dos textos que foram localizados e que mais se destacaram, seja pela sua incidência ou pela relação de sentido que este apresenta com a obra. Desta forma, procuramos evidenciar, como ocorre o fenômeno intertextual entre eles. Para tanto, lançamos mão da teoria da intertextualidade, das técnicas da literatura comparada, da teoria do dialogismo e da transtextualidade, com o propósito de compreendermos como ocorre o diálogo entre o romance selecionado e os textos literários presentes na obra.

Para embasarmos esta pesquisa, iniciaremos conceituando a teoria da intertextualidade, cunhada por Julia Kristeva (KRISTEVA, citada em SAMOYAULT, 2008, p. 15) a qual afirma que "[...] a intertextualidade é a relação entre um ou mais signos presente em outro". Assim sendo, partimos do conceito de que a obra selecionada apresenta uma relação intertextual, visto que, ao lê-la, é possível fazermos inferências com diversos outros textos de inúmeros autores. Ainda falando a respeito da intertextualidade, podemos apontar o que Kristeva diz acerca da composição dos textos. Para ela "[...] todo texto se constrói como um mosaico de citações, todo texto é absorção e transformação de um outro texto" (p. 16).

Ademais, Tiphanie Samoyault (2008, p. 10) nos apresenta alguns conceitos que, por sua vez, podem ser aplicados nesta análise, sendo eles "Citação, alusão, referência, pastiche, paródia, plágio, colagens de todas as espécies, as práticas de intertextualidade se repertoriam facilmente e se deixam descrever". Essas especificidades serão utilizadas como um meio de auxiliar a compreender os diálogos presentes na obra.

Outrossim, podemos inferir que as relações intertextuais presentes na obra estabelecem, ainda, uma outra série de relações entre si, isto, é uma espécie de diálogo entre elas, de acordo com o que propõe Mikhail Bakhtin (2016) em seus estudos acerca do dialogismo. Para o autor, todo texto é duplamente dialógico, "Ao falar do discurso do outro, não podemos deixar de ocupar alguma posição dialógica em relação a ele” (p. 147). Consequentemente, entende-se 
que o dialogismo contempla a relação entre seus interlocutores e com outros textos, como se todo texto demonstrasse alguma voz de um texto anterior. Portanto, os discursos são construídos a partir do discurso do outro, isto é, daquilo que já foi dito/escrito anteriormente. Bakhtin (2016, p. 141) sustenta, ainda, que na linguagem do "romance encontramos todas as mais diversas modalidades de diálogo". Logo, verificamos que o dialogismo se faz presente nos textos de maneira geral e, especialmente, nos discursos cuja pesquisa versa.

Prosseguindo com as teorias selecionadas, temos as contribuições de Gérard Genette (2006, p. 8), que define a relação entre textos como "[...] sem dúvida restritiva, como uma relação de copresença entre dois ou vários textos, isto é, essencialmente, e o mais frequentemente, como presença efetiva de um texto em um outro". Além disso, o autor delimita as relações intertextuais em um sentido mais restrito, denominadas por relações transtextuais, desse modo, sempre que nos reportarmos à transtextualidade estamos nos referindo ao conceito de Genette, o qual utiliza a expressão como uma terminologia abrangente, ou seja, um termo guarda-chuva que incorpora as demais relações entre textos. Veremos estas relações em detalhes no decorrer da análise.

Assim, por meio das teorias já apontadas, infere-se que a literatura, normalmente, estará ligada às histórias pregressas, já contadas e recontadas, por mais que os enredos não sejam visivelmente tão convergentes. Em um texto sempre haverá reminiscência de outros textos, seja de forma direta ou não. Samoyault (2008, p. 74) diz que escrever é reescrever, "Poderíamos assim enunciar sob forma de pleonasmo: a literatura só existe porque já existe a literatura”.

Portanto, por meio do arcabouço teórico apontado, seguiremos com a análise de alguns trechos do romance Que fim levaram todas as flores (2019), de Otto Leopoldo Winck. O objetivo deste estudo é de clarificar como o romance e os textos literários nele encontrados estão entrelaçados e, ainda, como eles são utilizados na construção de sentidos da obra.

\section{A REVERBERAÇÃo LiterÁRIA: DiÁLOGo ENTRE TEXTOS}

Fundamentando-se em alguns dos pressupostos já apresentados, iniciamos esse artigo discutindo a relação intertextual do título da obra Que fim levaram todas as flores. Oriundo de uma canção do extinto grupo musical Secos \& Molhados ${ }^{1}$, a canção foi lançada em 1978, e foi uma das mais executadas daquele ano. Ressalta-se, ainda, que a narração também transpassa esse período. Desse modo, observa-se uma referência alusiva relacionada à música. Solange Ribeiro de Oliveira (2003, p. 39), enfatiza que "a alusão musical potencializa os vários constituintes textuais, indispensáveis à leitura, ilustrando a importância da imagem musical para os estudos literários". Tal relevância abordada pela autora pode ser associada ao caráter estético, cultural e ideológico que a música sugere. Neste caso, em especial, pois a música que dá título

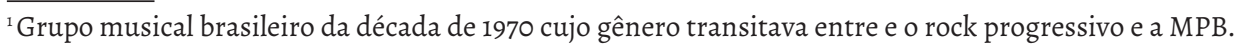


à obra pode ser relacionada ao Zeitgeist ${ }^{2}$ que vigorava na época em que boa parte da narrativa é descrita. Ainda sobre a presença do título da música denominar a obra em questão, podemos afirmar que essa ocorrência dentro do texto literário caracteriza uma relação intermidiática. Conforme aponta Irina Rajewsky (2012, p. 18) "[...] aquelas configurações que têm a ver com um cruzamento de fronteiras entre as mídias". Logo, infere-se que, além de intertextual a relação é também intermidiática. Concomitantemente, Julio Plaza (2010, p. 2) assevera que "a arte não se produz no vazio. Nenhum artista é independente de predecessores e modelos". Assim sendo, assimila-se que as produções artísticas tendem a manter um certo diálogo entre si, seja de maneira proposital ou não.

Com efeito, vale mencionar o que o próprio Otto Leopoldo Winck (2016, p. 7) - no prefácio da obra Assim transitam os textos: ensaios sobre a intermidialidade -, menciona a respeito da relação e da criação literária "Afinal, não há fonte, uma origem primeva, uma imago primordial, que deva ser restaurada ou recuperada. E não havendo fonte ou foz, original ou cópia, não há hierarquias, apenas uma rede complexa de signos em rotação". Posto isso, salienta-se que a presença de referências intertextuais e, nesse caso, especialmente, intermidiática, são partes constituintes da criação literária, portanto, deverão e serão analisadas sob a perspectiva de como elas dialogam entre si, e não com o intuito de localizarmos quais são as obras-fonte ou "originais".

Avaliando a obra como um todo, cabe mencionar que, embora a intenção deste estudo não seja de caráter quantitativo, é válido registrar que a obra apresenta um número bastante elevado de referências literárias, pois, até o momento, constatamos em torno de duzentas menções diferentes ${ }^{3}$, o que demonstra que o romance está intrinsecamente marcado pela intertextualidade.

Para melhor elucidar, selecionamos, inicialmente, um trecho da obra cujas menções a outros textos são significativas, pois além de localizadas já nas primeiras páginas do romance - da primeira parte ${ }^{4}$, as menções estão relacionadas a nomes da literatura nacional, um deles à prosa, o outro à poesia, são eles: Machado de Assis e Olavo Bilac. Quanto ao trecho referente à obra de Machado, notamos que além de uma referência direta, ou melhor, explícita, o autor parece se apropriar da mesma ideia do defunto-autor:

- Vejam o começo, por exemplo, de Memórias póstumas de Brás Cubas. E ele abriu um dos vários volumes que trouxera e leu:

\footnotetext{
${ }^{2}$ Termo alemão cuja tradução significa espírito da época, espírito do tempo ou sinal dos tempos. Significa, em suma, o conjunto do clima intelectual e cultural do mundo, numa certa época, ou as características genéricas de um determinado período de tempo.

${ }^{3}$ Disponível em: https://pt.scribd.com/document/472651442/Intertextualidade-Em-QFLTF.

${ }^{4}$ Winck (2020) afirma, em recente entrevista, que o romance é composto por uma moldura, três capítulos e uma seção de apêndice. O trecho em questão está localizado na primeira e segunda páginas da moldura da obra, nas páginas que convencionamos chamar de "cinzas".
} 
- "Algum tempo hesitei se devia abrir estas memórias pelo princípio ou pelo fim, isto é, se poria em primeiro lugar o meu nascimento ou a minha morte." Genial, não é? Aqui já se esboça o clima desse livro, a sua ironia, o seu tom. (WINCK, 2019, p. 2).

No trecho acima, o autor utiliza uma passagem do primeiro capítulo de Memórias póstumas de Brás Cubas (1881), de Machado de Assis, intitulado "1. Óbito do autor" (ASSIS, 2015, p. 33) cujos primeiros parágrafos são utilizados como uma espécie de abertura da obra, a fim de situar o seu leitor. Concomitantemente, a mesma abordagem é notada no livro de Winck, assim, é possível inferirmos que, talvez, o autor esteja se referindo ao próprio clima do livro que se apresenta, visto que Que fim levaram todas as flores é também um livro de memórias escrito pelo narrador-personagem Ruy Dalla Costa, e não apenas à obra de Machado de Assis, essa atmosfera pode ser notada no seguinte trecho: "Aqui já se esboça o clima desse livro, a sua ironia, o seu tom" (p. 2). De acordo com Samoyault (2008, p. 51) "a alusão depende mais do efeito de leitura que as outras práticas intertextuais: tanto pode não ser lida como pode também o ser onde não existe”. Assim, verificamos que além da citação, sinalizada pelas aspas e pela menção ao nome de Machado, há a presença de um trecho alusivo, em que a leitura será feita ou não de acordo a depender da bagagem cultural do leitor.

Já no que diz respeito ao trecho em que Bilac é mencionado, nota-se uma situação oposta: "Nosso maior parnasiano, Bilac, é no fundo um romântico enrustido" (WINCK, 2019, p. 1). Neste excerto, é possível afirmarmos que se trata de uma citação, dado que o autor cita o nome de Bilac explicitamente. Samoyault (2008, p. 49) corrobora afirmando que "com a citação, em compensação, a heterogeneidade fica nitidamente visível entre texto citado e texto que cita [...] faz parecer a relação do autor que cita com a biblioteca”. Percebemos aqui, como em outras citações literárias do romance Que fim levaram todas as flores, não somente a presença de uma simples catalogação de obras, mas sim uma tentativa constante do autor em demonstrar que tais obras seriam de grande importância na formação da personalidade da personagem principal, Ruy Dalla Costa, como na expressão "um romântico enrustido" em que se demonstra esse traço da personalidade de Ruy, um rapaz interiorano, com dificuldades para expressar seus sentimentos, que vê o amor ainda de uma forma idealizada.

Adiante, não poderíamos deixar de registrar a respeito da abertura do primeiro capítulo da obra, pois já durante o parágrafo inicial é possível observamos que o autor lança mão de um texto clássico da literatura francesa, vejamos, a seguir, como essa relação é apresentada no livro:

Estávamos em aula quando entrou o diretor, seguido de um novato, vestido de maneira simples, mas elegante. Os que cochilavam despertaram e todos nos pusemos de pé, atabalhoadamente. O diretor fez sinal para que nos sentássemos. Depois, voltando-se para o professor: 
- Bom dia, professor Ermelino. Eis um aluno que acaba de vir de Rolândia, com ótimas notas e excelentes recomendações. (WINCK, 2019, p. 21).

Como já dito, o trecho em questão faz parte da abertura da obra de Winck, que, aliás, corresponde ao primeiro parágrafo - praticamente na íntegra -, do romance Madame Bovary (1856), de Gustave Flaubert (1821-1880).

\begin{abstract}
Estávamos em aula quando o Diretor entrou, seguido de um novato, vestido à paisana e de um servente carregando uma grande carteira. Os que dormiam acordavam e todos nos levantamos como se tivéssemos sido surpreendidos durante o trabalho. O Diretor fez sinal para que nos sentássemos; depois, voltando-se para o inspetor de alunos:- Senhor Roger - disse-lhe a meia voz -, eis um aluno que lhe recomendo; vai para o quinto ano. (FLAUBERT, 2010, p. 1).
\end{abstract}

Cabe salientar que o trecho empregado não apresenta nenhuma marca tipográfica, tais como: aspas, itálico ou outro acessório que possibilite ao leitor a identificação do texto de Flaubert. Ademais, nota-se pequenas diferenças, provavelmente, em relação ao uso de traduções ou edições, além disso, verifica-se que há diminutas omissões, no entanto, a ideia central do parágrafo de Madame Bovary prevalece no texto. Assim sendo, de acordo com os pressupostos de Samoyault (2008, p. 49), constatamos que tal ocorrência, quando empregada de modo silencioso, isto é, quando ocorre "a ausência total de tipografia própria transforma a citação em plágio, cuja definição mínima poderia ser a citação sem aspas, a citação não marcada”. Ainda a respeito desse episódio, Gérard Genette (2010, p. 14), destaca que “[...] sua forma menos explícita e menos canônica é a do plágio [...], que é um empréstimo não declarado”. Posto isso, fica evidente que tais argumentos explicam com muita clareza o fenômeno intertextual condizente neste trecho, de modo que se pode inferir que o plágio é a tipologia que melhor define essa presença. Samoyault (p. 52) reitera que "Sua identificação depende da cultura e da sagacidade do leitor, o que torna a relação intertextual aleatória [...] o 'fundido' atinge toda a matéria do texto". Portanto, podemos afirmar que o texto de Flaubert aparece de modo unificado ao texto de Winck, que por sua vez, exige um pouco mais da memória literária do leitor, para que seja reconhecido. Ambas obras têm nesse primeiro capítulo a demonstração da chegada de uma personagem que mudaria a perspectiva de vida das protagonistas, ampliando seus horizontes de conhecimento, principalmente literários, e lhes dando um novo modelo de vida e personalidade. Tanto Madame Bovary (1856), de Flaubert, quanto Que fim levaram todas as flores (2019), de Winck, tratam da formação intelectual de um jovem (Charles Bovary e Ruy Dalla Costa, respectivamente) e de seu amadurecimento, sendo a escola esse primeiro ponto de encontro e ainda mais, palco da formação intelectual através dos estudos regulares e da relação de amizade que se faz entre as personagens. 
Outro quesito que pode ser apontado é a presença das epígrafes, pois o autor não utilizou apenas um trecho de outro autor, como quase sempre acontece, na grande parte das obras publicadas, mas sim quatro. Todas as menções são identificadas pelas suas autorias, sendo elas: Jean-Jacques Rousseau (1712-1778), Charles Dickens (1812-1870), T. E. Lawrence (1888-1935) e Jamil Snege (1939-2003). Genette (2006, p. 7) afirma que "[...] sua forma mais explícita e literal é a prática tradicional da citação”. Assim sendo, nota-se, então, mais uma presença intertextual em forma de citação.

Estas menções estão relacionadas ao enredo da obra, servindo de reflexão para o que o leitor irá ler em seu enredo. A primeira delas remete ao Livro IV, de Emílio ou Da Educação em que Rousseau explica aquilo que hoje compreendemos por adolescência: "Nascemos, por assim dizer, duas vezes: uma para existir, outra para viver; uma para a espécie, outra para o sexo" (ROUSSEAU, citado em WINCK, 2019, p. 11) e dialoga com as mudanças sofridas pelo personagem Ruy ao longo de sua adolescência no interior do Paraná e com sua posterior vinda para a capital Curitiba. Antes de conhecer Adrian', Ruy existia. Após a sua iniciação intelectual (e sexual) nasce um outro rapaz: articulado, literato e politizado. Em sua terra natal vivia sem grandes sonhos, preso às amarras patriarcais impostas pela família, pela escola e pela monotonia citadina; na capital nascera um novo jovem: livre, autodidata, partícipe da cena cultural, intelectual e universitária de Curitiba.

Na segunda epígrafe, retirada do início do romance histórico "Um conto entre duas cidades" (1859), de Charles Dickens (1812-1870), enredo inspirado na Revolução Francesa, em que o autor se volta para a observação dos indivíduos pertencentes aos mais diversos estratos da sociedade francesa - desde a aristocracia, passando pela burguesia, até o povo miserável de Paris; a outra cidade do título remete a Londres.

Aquele foi o melhor dos tempos, foi o pior dos tempos. Foi a idade da razão, foi a idade da insensatez. A época da crença, foi a época da incredulidade, a estação da Luz, a estação das Trevas, a primavera da esperança, o inverno do desespero, tínhamos tudo diante de nós, não tínhamos nada diante de nós, todos iríamos direto ao paraíso, todos iríamos direto no sentido oposto. (DICKENS, citado em WINCK, 2019, p. 11)

Percebemos a intertextualidade quando em Que fim levaram todas as flores (2019) temos o narrador-personagem Ruy passando por semelhantes provações: tanto em sua cidade natal, quanto em Curitiba eram tempos difíceis, marcados pela repressão política, principalmente. Se por um lado aquele fora um período de grande amadurecimento para ele, pelo outro fora também um período difícil de posicionamento político e luta. Era preciso fazer a revolução, mesmo que parecesse insensato. Era preciso acreditar que se poderia mudar o curso da história.

\footnotetext{
${ }^{5}$ Em entrevista recente, o autor afirma que o nome de personagem é uma alusão ao personagem homônimo em Doutor Fausto: a vida do compositor alemão Adrian Leverkühn, contada por um Amigo (1947), do escritor alemão Thomas Mann.
} 
Um período de trevas, mas de busca pela luz. Um período em que a contracultura era efervescente, em que tudo parecia possível de ser mudado, como acreditaram, em um primeiro momento, aqueles que derrubaram a monarquia na França, mas que depois veriam o poder político somente mudar de mãos, para as mãos da burguesia.

Na cena seguinte temos uma citação do romance Os sete pilares da sabedoria ${ }^{6}$ (1922), do escritor inglês T. E. Lawrence. Na obra narra-se a participação de seu autor, conhecido universalmente como Lawrence da Arábia, no movimento nacionalista árabe contra a dominação turca, como parte do esforço britânico na Primeira Guerra Mundial para derrotar a Alemanha, da qual a Turquia era aliada. Seu título é uma alusão a uma frase da Bíblia, no Livro dos Provérbios (IX,1). ${ }^{7}$

Todos os homens sonham, mas não da mesma forma. Os que sonham de noite, nos recessos poeirentos das suas mentes, acordam de manhã para verem que tudo, afinal, não passava de vaidade. Mas os que sonham acordados, esses são homens perigosos, pois realizam os seus sonhos de olhos abertos, tornando-os possíveis" (LAWRENCE, citado em WINCK, 2019, p. 11).

Este sonhar está relacionado ao que almejava a geração dos anos 1968 - o ano que não acabou $^{8}$ - , que "acordados" para as grandes questões do mundo, manifestavam a vontade de mudança através de seus "cantos de protesto" presentes nas obras literárias que liam e debatiam, nos filmes do Cinema Novo, na moda (cabelos compridos, minissaia, roupas coloridas), no comportamento (uso de drogas lisérgicas, ruptura com estruturas sociais solidificadas no passado), sexualidade (amor livre, pílula anticoncepcional), músicas de protesto. Ruy e seus dois colegas, Adrian e Elisa, vivem esse Zeitgeist de forma comedida em sua cidade interiorana, através de suas descobertas literárias, filosóficas, artísticas e musicais, bem como de suas incursões pela militância por meio de reuniões em seu recém-formado Grêmio Estudantil —é como se esse período fosse o de preparação, tanto intelectual quanto de maturidade para o que viria posteriormente, já na capital Curitiba: a militância inflamada e a luta armada.

Na última epígrafe: "Minha Curitiba é um cão ladrando para a lua da memória. E o único bonde que temos está parado. Não vai a lugar nenhum" (SNEGE, citado em WINCK, 2019, p. 11) retirada da coletânea de crônicas Como se tornar invisível em Curitiba (2000), do escritor curitibano Jamil Snege (1953-2003), temos uma referência ao último capítulo das

\footnotetext{
${ }^{6}$ Em 1962, a obra é adaptada para o cinema, sob a direção de David Lean, sob o título Lawrence da Arábia, vindo a ganhar sete Oscars e o reconhecimento do American Film Institute como um dos dez melhores filmes de todos os tempos.

${ }^{7} \mathrm{~A}$ sabedoria já edificou a sua casa, já lavrou as suas sete colunas.

${ }^{8} \mathrm{Em}$ 1988, vinte anos após a decretação do Ato Institucional n ${ }^{\circ} 5$ (AI-5), o jornalista Zuenir Ventura publicara "1968 - O Ano Que Não Terminou". Tendo como tema principal a resistência à ditadura, a obra retrata os intensos debates em relação às formas de luta contra o regime, tendo o movimento estudantil, a opção pela luta armada e a resistência dos artistas destaque especial. Na obra fora publicada a ata da $43^{a}$ sessão do Conselho de Segurança Nacional, até então desconhecida do público. Nela foi aprovado o AI-5, que aprofundou a natureza arbitrária e violenta da ditadura.
} 
memórias da personagem Ruy que, já envelhecido, tem seu último encontro com o grande amigo e mentor Adrian no tradicional Bar Stuart em Curitiba. Nada é como no passado: os ideais revolucionários deram lugar a uma vida pacata de jornalista aposentado para Ruy e para uma vida burguesa, liberal e conservadora de empreiteiro da construção civil para Adrian; os lugares mudaram muito nos últimos anos: o comércio de rua deu lugar aos Shopping Centers, as fachadas mudaram de nome, outras lojas surgiram, outras deixaram de existir. Há um sentimento de frustração em ambos, pois sabem que a vontade de mudança arrefeceu não somente neles, mas aparentemente em boa parte das pessoas. A Curitiba deles é uma cidade que já não existe mais, as memórias daqueles tempos ficaram estagnadas, esperando uma luz da memória acendê-las, estão estagnadas como o último bonde de Curitiba, colocado como monumento na Rua Quinze de Novembro. O encontro dos amigos é somente isso: uma lua na memória dos tempos perdidos que viveram, sem a promessa concreta de um reencontro.

Adiante, é possível notar que o autor não lança mão apenas de textos da literatura, como também faz uso de diversas referências bíblicas em sua obra, vejamos como o romancista insere um excerto da Bíblia dentro da prosa: "Afinal, não éramos ricos, não tínhamos patrimônio, bens de raiz - e para todas as pessoas nessas condições está lá a maldição bíblica de comprar o pão com o suor do próprio rosto" (WINCK, 2019, p. 27). Percebe-se novamente que há uma citação explícita, desta vez à Bíblia, pois o autor não oculta a fonte do texto que fora parafraseado. No entanto, em outro momento da narrativa, localizamos um trecho que o autor realiza um outro tipo de referência:

Resolvido esse problema, da fome, da pobreza, da miséria, as pessoas vão poder se dedicar à arte, ao convívio, à vida... "O reino da liberdade só começa quando o trabalho deixa de ser determinado pela necessidade" - citou Adrian." (WINCK, 2019, p. 110).

Nessa passagem, o que pode ser destacado é que o autor realiza uma menção de forma explícita, Samoyault sustenta que (2008, p. 49) “[...] as aspas, os itálicos, a eventual separação do texto citado distinguem os fragmentos emprestados [...] basta uma dessas marcas para assinalar a citação [...]". Assim, o excerto entre aspas utilizado por Winck demonstra ao leitor que tais trechos se referem a outros textos. Ademais, cabe dizer que o trecho em questão além de servir como uma referência bíblica, pois alude ao "reino da liberdade", ainda faz parte de uma obra de Karl Marx, o trecho é oriundo da obra O capital. ${ }^{\text {" }}$

Ambos trechos demonstram os ideais que a personagem Adrian, em Que fim levaram todas as flores (2019), tentava ensinar aos colegas, principalmente Ruy. Adrian faz uso dessas citações como forma de legitimar os ideais socialistas em que acreditava, fazendo com que os outros jovens também passassem a ter interesse, compreensão e, principalmente, engajamento

${ }^{9}$ MARX, Karl. O capital, Livro III, Tomo II. Tradução Regis Barbosa e Flávio R. Kothe São Paulo: Nova Cultural, 1986. 
político. Essas ideias reverberariam logo após, quando os três amigos, Ruy, Adrian e Elisa, participariam ativamente da vida política e das lutas estudantis na capital Curitiba.

Partindo para outros aspectos notórios da obra, salienta-se que Winck consegue inserir em uma única página uma dezena de diferentes autores, o fato é que, por muitas vezes, as menções estão muito bem entrelaçadas ao contexto da narrativa, logo, são incorporadas à voz do narrador e contribuem para que o leitor dê um amplo sentido ao texto. Segue um pequeno exemplo desta ocorrência.

Além disso, fomos aquinhoados pelos deuses: éramos contemporâneos dos últimos grandes literatos do século: anões sobre os ombros de gigantes como Guimarães Rosa, Otto Maria Carpeaux, Érico Veríssimo, John Steinbeck, Jorge Luis Borges, e Vladimir Nabokov, todos ainda vivos e atuantes. (WINCK, 2019, p. 57)

No trecho acima, averígua-se que diversos escritores são citados, aliás, este recurso é utilizado por inúmeras vezes ao longo do romance, com um número muito grande e diversificado de autores -, de modo a criar uma "atmosfera literária" na obra. Portanto, conjetura-se que a inserção dessas referências, ou seja, a menção a esses diversos autores e autoras, pode ser associada, provavelmente, ao rebuscamento e ao acervo cultural, tanto do autor, em virtude de sua formação acadêmica e intelectual, quanto do personagem-narrador da obra, que se demonstra um jovem de vanguarda, ávido em busca de engendrar uma revolução social. Como mencionado anteriormente, compreendemos essas citações como forma de expressar o amadurecimento intelectual da personagem Ruy que, conforme vai lendo as obras desses autores, vai as interpretando e tomando suas ideais para si.

Prosseguindo, porém, ainda na mesma página 57, nos deparamos com uma outra presença e forma de recursos intertextuais relevantes. Desta vez, o narrador utiliza as referências literárias para acentuar o sentido e ampliar as possibilidades de leitura do seu leitor. Vejamos o excerto:

A minha geração que, sofreu também o forte influxo do cinema e da música popular, foi provavelmente a última geração literária. Ou, pelo menos, a última geração poética: a última em que para uma parcela significativa de seus membros a poesia nunca se reduziu a mera matéria escolar [...]

Como quase todo mundo de nossa época, começamos, adolescentes em crise, por Manuel Bandeira e Cecília Meireles:

- "Eu faço versos como quem chora de desalento... de desencanto... Fecha o meu livro, se por agora não tens motivo nenhum de pranto."

- "És precária e veloz, Felicidade. Custas a vir e, quando vens, não te demoras. Foste tu que ensinaste aos homens que havia tempo, e, para te medir, se inventaram as horas." (WINCK, 2019, p. 57-58) 
Analisando o trecho acima, percebemos que as referências literárias utilizadas enfatizam o sentido e estendem as possibilidades de leitura do texto. As referências ali apresentadas são caracterizadas como citações, visto que os poetas modernistas são citados de maneira explícita e não alusiva, além disso, o texto fora grafado com as marcas textuais (aspas), ratificando que a autoria pertence a outros nomes. Quanto aos poemas utilizados, verificou-se que o primeiro é de Manuel Bandeira, intitulado Desencanto ${ }^{10}$ (1912), já o de Cecília Meireles é denominado: Epigrama n. $2^{11}$ (1972). Nesse sentido, cabe trazer o que Roland Barthes (2004, p. 64) diz a respeito das conexões e sentidos criados pelo leitor “[...] há um lugar onde esta multiplicidade se reúne, e esse lugar não é o autor, como se disse até o presente, é o leitor [...]”. Portanto, depreende-se, assim, que a inserção dos poemas expande o leque de interpretação do texto e, ainda, enriquece-o, pois oferece ao leitor acesso a outros autores e outros gêneros literários.

Essas e outras referências poéticas estão presentes em diversos momentos do enredo do romance Que fim levaram todas as flores: Ruy as cita frequentemente, muitas vezes, as associando a alguma passagem marcante de sua vida, como nos dois poemas mencionados acima, em que se utiliza das imagens criadas pelo eu lírico para expressar como fora a sua iniciação na leitura de poesia, relacionando-os aos momentos de sua própria vida.

Por fim, em meios aos exemplos apresentados, ressaltamos que as ocorrências intertextuais observadas estão relacionadas à constituição de sentido da obra, além de fazerem parte daquelas lacunas que serão preenchidas pelos leitores (as) por meio de sua bagagem cultural, de suas leituras prévias e de seu conhecimento de mundo. Nesse sentido, vale ressaltar o que Antoine Compagnon (1999, p. 149) afirma sobre o tema:

O sentido é, pois, um efeito experimentado pelo leitor, e não um objeto definido, preexistente à leitura [...] O texto literário é caracterizado por sua incompletude e a literatura se realiza na leitura [...] O objeto literário autêntico é a própria interação do texto com o leitor.

Posto isso, verificamos que o texto literário além de dialogar com os textos que o antecedem, promove um diálogo com o próprio leitor, dado que viabiliza ao público a oportunidade de realizar novas conexões e as mais diversas inferências, afinal é pelos encadeamentos entre textos e pelos preenchimentos de lacunas que algumas construções de sentido da obra vão sendo construídos em sua totalidade.

\footnotetext{
${ }^{10} \mathrm{Eu}$ faço versos como quem chora/ De desalento... de desencanto.../Fecha o meu livro, se por agora/ Não tens motivo nenhum de pranto.// Meu verso é sangue. Volúpia ardente.../ Tristeza esparsa... remorso vão.../ Dói-me nas veias. Amargo e quente,/ Cai, gota a gota, do coração.// E nestes versos de angústia rouca/ Assim dos lábios a vida corre,/ Deixando um acre sabor na boca.// - Eu faço versos como quem morre.

${ }^{11}$ És precária e veloz, Felicidade./ Custas a vir e, quando vens, não te demoras./ Foste tu que ensinaste aos homens que havia tempo,/ e, para te medir, se inventaram as horas.// Felicidade, és coisa estranha e dolorosa:/ Fizeste para sempre a vida ficar triste:/ Porque um dia se vê que as horas todas passam,/ e um tempo despovoado e profundo, persiste.
} 


\section{CoNSIDERAÇõES FINAIS}

Constatamos que a intertextualidade presente na obra Que fim levaram todas as flores não podem ser dissociadas de sua trama sem causar prejuízos, isto é, é impossível desconectar as obras mencionadas e ou aludidas, da narrativa, em virtude de estarem intimamente vinculadas ao enredo. Este vínculo, por sua vez, se dá de variados modos, por meio das diferentes e inúmeras relações intertextuais observadas, por exemplo, com as alusões, citações e "plágio", que compõe um romance costurado entre múltiplos textos. Além do mais, observamos que a escrita criativa - um dos recursos explorados na trama - pode ser relacionada ao uso abundante das referências apontadas e, evidentemente, de tantas outras mais, que seria impossível abordarmos neste estudo.

No nosso entender, ao situar o enredo do romance em uma moldura que ocorre durante um curso de Escrita Criativa, Winck propõe uma espécie de jogo, em que se pretende aguçar o leitor tanto pela memória dos textos que este já leu, como também pela curiosidade em buscar esses textos apresentados. Tanto as obras como autores presentes na obra nos parecem ser uma reverberação textual do curso de Escrita Criativa frequentado por Ruy, bem como durante seu período de formação intelectual em sua cidade do interior, quando da amizade inicial com Adrian, assim como de suas vivências intelectuais na provinciana Curitiba dos anos 1970. Cada trecho aludido, parafraseado, "plagiado" aqui constatado, descortina uma imensa gama de referências textuais, algumas delas alusivas e, portanto, mais difíceis de serem apreendidas, mas que funcionam ao leitor como um completo guia literário daquele período.

Ao nomear as obras que leu, relacionando seus enredos com o que vivia naquele período, Ruy demonstra seu crescimento intelectual, assim como de seu amadurecimento. Do menino interiorano que lia a coleção enciclopédica "Tesouros da juventude" (1958) ou as revistas de variedades, em especial a Reader's Digest ${ }^{12}$, ao homem maduro e intelectualizado, conhecedor e leitor crítico dos grandes mestres da literatura e da filosofia mundial, capaz de citar JeanPaul Sartre (1905-1980) e trechos inteiros do Livro vermelho (1964), de Mao Tsé-Tung (1893-1976).

Essa relação entre crescimento intelectual e amadurecimento com o que se vivencia em vida ou através da literatura é uma característica do Bildungsroman.$^{13}$ Ruy tem em Adrian um modelo sólido de intelectualidade e militância, sendo para ele quase impossível se desvencilhar de tais influências. Adrian, assim como Elisa, é um intelectual experiente, conhecedor de boa parte da literatura ocidental, assim como da filosofia e da música - e é ele que recomenda e empresta livros, discos, que traz as novidades do mundo para Ruy, levando-o ao amadurecimento. Adrian representa uma luz no presente iluminando em potência o sonhado futuro (a

\footnotetext{
${ }^{12}$ Em circulação no Brasil desde 1942, trazida por Robert Lund, fundador do Grupo Lund Editoras Associadas, tratando, de forma leve, de assuntos diversos, incluindo saúde, anedotas, conhecimentos gerais e biografias diversas.

${ }^{13}$ Romance de formação. Gênero de romance originário da Alemanha, que fala das primeiras lutas e a educação emocional de um protagonista jovem, que cresce e amadurece durante o processo.
} 
revolução). Em contrapartida, Ruy é aquele que, ao final do romance, na cena do Bar Stuart, traz as notícias da cidade natal interiorana - Ruy carrega a lamparina do passado, difuso, controverso, esquecido.

Winck reconstrói o passado através do cenário intelectual dos anos 1960: Adrian, Elisa e Ruy, além das leituras, se relacionam com a diversidade artística de Curitiba, desde artistas plásticos até autores locais, como Paulo Leminski e Jamil Snege, entre outros. O próprio autor, ao citar esses escritores e obras, através das personagens, demonstra também seu processo de formação intelectual - a "lista" de Ruy também é a sua.

Em entrevista recente para o "Projeto Quarentena", canal voltado para a divulgação de conteúdos produzidos para os estudantes do curso de Letras da PUCPR, o professor Otto Leopoldo Winck cita várias obras que o auxiliaram na escrita do presente romance: Tempo sujo (1968), de Jamil Snege; O guardador de fantasmas (1996), de Fábio Campana; Memórias de neblina, de Luíz Manfredini; HQ 1968 Ditaduras abaixo, de Teresa Urban; o jornal O Pasquim, além de dicionários de gírias brasileiras, livros sobre as árvores, ruas e avenidas de Curitiba. Possivelmente haverá reverberações, em forma de alusão, destas obras na obra de Winck, demonstração clara de que os textos "caminham", entrelaçam-se numa contínua intertextualidade.

\section{REFERÊNCIAS}

BAKHTIN, M. Os gêneros do discurso. Tradução de Paulo Bezerra. São Paulo: Editora 34, 2016.

BARTHES, R. A morte do autor. In: O rumor da língua. Tradução de Mário Laranjeira. São Paulo: Martins Fontes, 2004, p. 57-64.

CAMPANA, F. O guardador de fantasmas. Curitiba: Travessa dos Editores, 1996.

COMPAGNON, A. O demônio da teoria: literatura e senso comum. Tradução de Cleonice Paes Barreto Mourão. Belo Horizonte: UFMG, 1999.

DICKENS, C. Um conto de duas cidades. São Paulo: Nova Cultura, 2002.

ENCICLOPEDIA Tesouros da juventude. Nova York: W. M. Jackson Inc. 1958. 18 vol.

FLAUBERT. G. Madame Bovary. Tradução de Fúlvia Maria Luiza Moretto. São Paulo: Abril, 2010.

GENETTE, G. Palimpsestos: a literatura de segunda mão. Tradução de Luciene Guimarães e Maria Antônia Ramos Coutinho. Belo Horizonte: UFMG, 2010.

LAWRENCE, T. E. Os sete pilares da sabedoria. Tradução de C. Machado. Rio de Janeiro: Record, 2015. MANFREDINI, L. Memória de neblina. 1. ed. Curitiba: Ipê Amarelo, 2011.

MAO, T. O livro vermelho: citações do comandante Mao Tse-Tung. São Paulo: Martin Claret, 2004. 
O PASQUIM. Rio de Janeiro, 1969 -. Semanal.

PLAZA, J. Tradução intersemiótica. 2. ed. São Paulo: Perspectiva, 2010.

QUARENTENA, Projeto. Conversa com Otto Leopoldo Winck sobre "Que fim levaram todas as flores". 2020. (9m24s). Disponível em: https://www.youtube.com/ watch?v=DJOv25SoCDo\&feature=youtu.be. Acesso em: 05 ago. 2020 .

RAJEWSKY, I. O. Intermidialidade, intertextualidade e "remediação": uma perspectiva literária sobre a intermidialidade. Tradução de Thaïs F. N. Diniz e Eliana Lourenço de Lima Reis. In: DINIZ, T. F. N. (Org.). Intermidialidade e estudos interartes: desafios da arte contemporânea. Belo Horizonte: UFMG, 2012. p. 15-45.

ROUSSEAU, J.-J. Emílio ou da educação. São Paulo: Difusão Europeia do Livro, 1968. p. 60-2 apud PILETTI, C. \& PILETTI N.

SAMOYALUT, T. A intertextualidade. Tradução de Sandra Nitrini. São Paulo: Editora Hucitec, 2008. SNEGE, J. Tempo sujo. Curitiba: Escala, 1968.

OLIVEIRA, S. R. de. Introdução à melopoética: a música na literatura brasileira. In: OLIVEIRA, S. R. de. et al. Literatura e música. São Paulo: Editora Senac São Paulo/ Instituto Itaú Cultural, p. 17-48, 2003.

URBAN, T. 1968: Ditaduras abaixo. Curitiba: Arte e Letra, 2008.

WINCK, O. L. Elogio da tra(d)ição: ou umas breves linhas à guisa de prefácio. In: REICHMANN, B. (Org.). Assim transitam os textos: ensaios sobre a intermidialidade. Curitiba: Appris, 2016.

WINCK, O. L. Que fim levaram todas as flores. Curitiba: Kotter Editorial, 2019.

Recebido para publicação em: 10 jun. 2021. Aceito para publicação em: 5 out. 2021. 